\title{
Merger leaves biotechnology partners anxious
}

Biotechnology companies are still waiting to determine the effects of the May 1997 merger between Hoffmann-La Roche (Basel, Switzerland) and Boehringer Mannheim (Mannheim, Germany) on their corporate alliances with the companies. The Swiss pharmaceutical company initiated an $\$ 11$ billion takeover of Corange, Boehringer Mannheim's parent company, in May 1997.

Some relationships seem untouched by the merger, Sequana Therapeutics (La Jolla, CA) and Boehringer Mannheirm initiated a $\$ 21$ million collaboration in May 1995 to identify genes involved in the progression and staging of osteoporosis and other bone diseases. "Based on our discussions with both parties, the merger will not effect our agreement at all," says Steve Sugino, vice president of business development at Sequana (now itself merger with Arris Phamaceutical [South San Francisco, CA]]). "The general theme is that we are looking at this [merger] as an opportunity to work more closely with

Debra Robertson is a freelance writer warking in Sam Dievo. CA.
Roche in osteoporosis and other target areas."

However, for other companies the merger implications are unclear. CollaGenex Pharmaceuticals, a Newtown, Pennsylvaniabased biotechnology company has a research collaboration with Boehringer Mannheim to test nowel matrix metalloproteinase inhibitors in a variety of animal models for cancer. The agreement includes an option for renewal after initial evaluation of the compounds. According to Brian Gallagher, president and CEO of CollaGenex, conversations with Boehringer Mamneim indicate that "no general decisions have been made in regard to the research programs." "Having been through the Bristol-Myers Squibb merger, I realize that it takes several months to evaluate all the programs and their merits," explains Gallagher.

The gene therapy specialist. GeneMedicine (The Woodlands, TX), has a more pressing deadline, however. As part of a collaboration with Boehringer Mannheim that started in July 1995, GeneMedicine began a phase I trial in August 1997 of a plasmid-borne interleukin-2 gene in a cationic gene-delivery system for the treatment of head and neck cancer. Boehringer Mannheim has an option, due on February 1, 1998, to extend this collaboration to other forms of cancer. By the beginning of December, however, the opaqueness of decision-making within the merged pharmaceutical giant meant that GeneMedicine was still uncertain whether Boehringer Mannhein would take up the option or whether a new partner would be needed.

There are some indications that already existing Roche agreements, too, may also be affected by the Roche-Corange merger. In early December 1997, Agouron Pharmaceuticals (La Jolla, CA) announced the termination of its broad based cancer-drug development partnership with koche. According to an Agouron spokesperson, "Roche made the decision to stop the cancer program prior to seeng the results of Thymitac, a cancer therapeutic targeted at liver, head, and neck cancer." "The decision, and disappointing performance of Thymitaq in phase II/III clinical trials, has forced Agouron to abandon the drug, But Agouron president and CEO Peter Iohnson is baffled by Roche's decision to "pull the plug" on the entire cancer program.

Debra Robertson
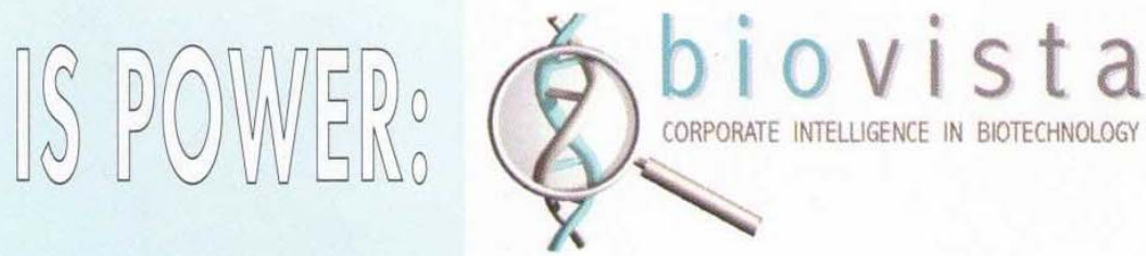

Pick up one of the biovista ${ }^{\mathrm{TM}}$ Industry Reviews \& Company Databases and join those who enjoy the advantage of quality corporate intelligence:

- COMBINATORICS

- CARBOHYDRATE THERAPEUTICS

USA EUROPE

701 East High St., \#315, Charlottesville, VA 22902

$\mathrm{Tel} / \mathrm{Fax}+18049846027$

14A Marathonos St., Athens 14343

GREECE

Tel +3012518701

Fax +3012520885

biovista@ath.forthnet.gr

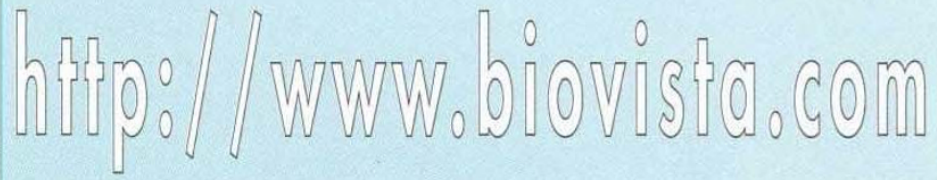

"The most broadly-spanning and comprehensive reviews of key platform biotechnologies"

Dr. Stelios Papadopoulos, Managing Director, PaineWebber

"The biovista ${ }^{T M}$ IR\&CD has helped Peptide Therapeutics to raise the profile of its RAPID ${ }^{T M}$ discovery technology - I find it a very useful resource." Dr. Paul Wallace, Business Development Manager, Peptide Therapeutics Ltd.

“...The biovista ${ }^{T M}$ report provides a great inventory of the major players and current trends."

Dr. David Ecker, VP and Managing Director, ISIS Pharmaceuticals 